\title{
Penguatan Perilaku Sehat Masyarakat Desa Bokor Kecamatan Tumpang Kabupaten Malang Melalui Sosialisasi Pemilahan Sampah Rumah Tangga
}

\author{
Nihayatu Aslamatis Solekah \\ UIN Maulana Malik Ibrahim Malang, Jl. Gajayana No.50, Dinoyo, Kec. Lowokwaru, Kota \\ Malang, Jawa Timur 65144 \\ Email: aslamatiss_1@pbs.uin-malang.ac.id
}

\begin{abstract}
ABSTRAK
Kegiatan pengabdian ini dilakukan di Desa Bokor Kecamatan Tumpang Kabupaten Malang. Kondisi obyek dampingan dapat diidentifikasi beberapa permasalahan yang muncul, adanya perilaku yang kurang tepat dari masyarakat bokor yang membuang sampah sembarangan. Mereka membuang sampah di sungai, dan pekarangan sehingga bisa mengakibatkan pencemaran lingkungan sekitar. Metode yang dipakai dalam pengabdian ini adalah PAR (participation action research). Langkah-langkah yang dilakukan dalam pengabdian ini diawali FGD dengan Pemerintahan Desa, Stake holder dan masyarakat itu sendiri, dilanjutkan dengan sosialisasi dan pendampingan perilaku masyarakat desa Bokor dengan memilah sampah organik dan unorganik, serta memberikan fasilitas tong sampah yang didistribusikan ke warga desa Bokor warga agar terjadi perubahan membuang sampah tidak disungai tapi dibuang pada tong sampah yang yang sudah disediakan. Sehingga mereka tidak lagi membuang sampah rumah tangganya di sembarang tempat dan sungai. Mitra kerja dalam pengabdian ini adalah karang taruna serta ibu PKK yang didukung sepenuhnya oleh Kepala desa dan perangkatnya.
\end{abstract}

Kata kunci: Pola Hidup Sehat; Sosialisasi; Pemilahan Sampah Organik

\begin{abstract}
This community service activity was carried out in Bokor Village, Tumpang District, Malang Regency. The condition of the assisted object can be identified several problems that arise, the existence of inappropriate behavior from the bokor community who littering. They throw garbage in rivers and yards so that it can cause pollution to the surrounding environment. The method used in this service is PAR (participation action research). The steps taken in this service began with an FGD with the Village Government, Stakeholders and the community itself, followed by socialization and mentoring the behavior of the Bokor village community by sorting organic and unorganic waste, as well as providing trash can facilities that were distributed to residents of the village of Bokor. There has been a change in disposing of garbage not in the river but discarded in the trash can that has been provided. So that they no longer throw their household waste in any place and river. The partners in this service are youth organizations and PKK mothers who are fully supported by the village head and his apparatus.
\end{abstract}

Keywords: Healthy Lifestyle; Socialization; Sorting Of Organic Waste

\section{PENDAHULUAN}

Persoalan lingkungan menjadi isu global, setelah semua elemen masyarakat menyadari akan bahaya yang ditimbulkan dari kerusakan lingkungan. Diantara kerusakan lingkungan yang sekarang urgent untuk diperhatikan adalah sampah. Setiap tahun sejumlah 
besar makanan terbuang dari produksi pangan sampai konsumsi. Aktivitas pemborosan makanan telah menjadi praktik rutin sehari-hari dan sebagian besar dari kerugian ini disumbangkan oleh konsumen di seluruh dunia (Bhatti, 2019; Sahil, 2016; Damanhuri, 2004). Schanes dkk. (2018) mengungkapkan dalam penelitiannya bahwa orang di atas 65 tahun memiliki kecenderungan untuk lebih sedikit membuang-buang makanan, sedangkan rumah tangga dengan anggota keluarga yang lebih muda cenderung membuang lebih banyak makanan. Hasil riset menunjukkan hal penting untuk diperhatikan bagi pembuat kebijakan terutama dalam konteks negara berkembang di mana terdapat populasi yang besar dan kesadaran pencegahan limbah makanan sangat rendah (Bhatti, 2019). Stangherlin, dkk. (2019) aspek penting yang semakin mendapatkan perhatian terkait dengan pengurangan limbah makanan agar tidak terjadi pemborosan. Pendorong dan hambatan untuk mengurangi limbah makanan dikategorikan dalam faktor kemasyarakatan, faktor personal dan faktor perilaku (Stangherlin dan Barcellos, 2018). Oleh karenanya isu yang diangkat dalam pengabdian ini adalah bagaimana merubah perilaku masyarakat dalam kaitannya dengan sampah.

Kegiatan pengabdian ini dilakukan di Desa Bokor Kecamatan Tumpang Kabupaten Malang yang merupakan kegiatan KKM UIN Maulana Malik Ibrahim Malang. Desa Bokor merupakan desa yang ada di Kecamatan Tumpang Kabupaten Malang. Batas wilayah Desa Bokor adalah untuk Sebelah Selatan: Desa Pulungdowo Kecamatan Tumpang, untuk Sebelah Utara: Desa Wringingsongo Kecamatan Tumpang, untuk Sebelah Timur : Desa Tumpang Kecamatan Tumpang dan untuk Sebelah Barat: Desa Slamet Kecamatan Tumpang. Sebagaimana gambar 1:

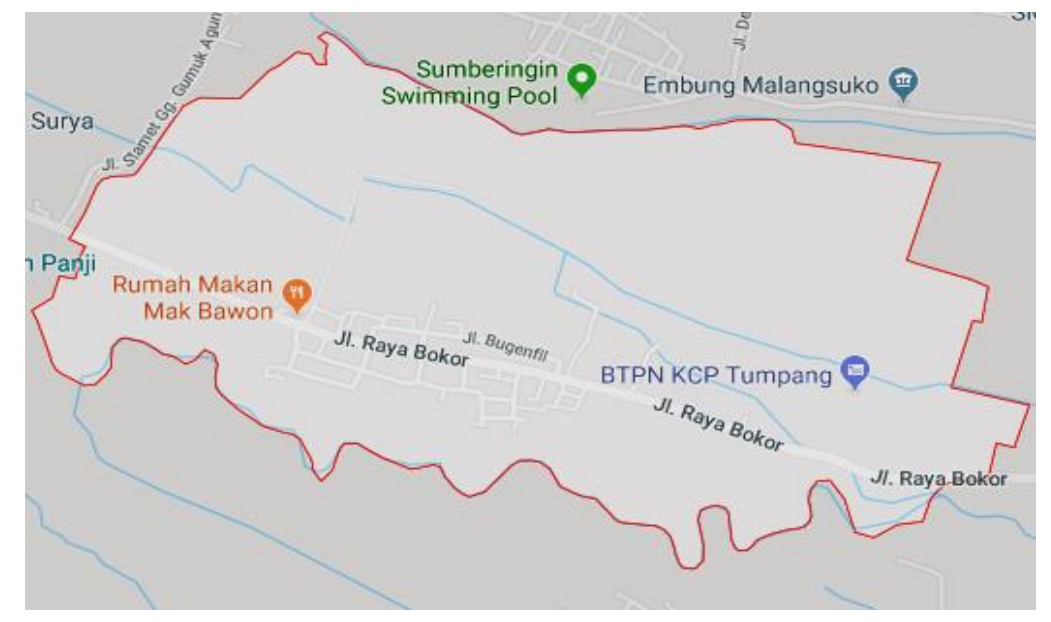

Gambar 1 Peta Geografis Desa Bokor

Berdasarkan data Administrasi yang ada di Kantor Desa Bokor Kecamatan Tumpang Kabupaten Malang, pada Akhir Desember 2017 tercatat Jumlah Penduduk Desa Bokor 
adalah 3220 yang terdiri dari 1603 laki-laki dan 1617 wanita. Dengan jumlah 1401 KK. Dari hasil observasi awal yang dilakukan maka dapat diidentifikasi beberapa permasalahan yang muncul: (1) Adanya perilaku yang kurang tepat dari masyarakat bokor yang membuang sampah sembarangan. Mereka membuang sampah di sungai, dan pekarangan sehingga bisa mengakibatkan pencemaran lingkungan sekitar. (2) Kurangnya pengetahuan dan pemahaman cara mengelola sampah dengan baik sehingga mereka tidak membedakan mana sampah yang bisa di daur ulang dan yang tidak. (3) Munculnya pemahaman yang salah tentang cara membuang panpers, mereka lebih suka membuang di sungai karena mereka percaya jika dibuang ditempat sampah akan dibakar dan bisa mengakibatkan ruam pada bayi-bayi mereka. (4) Belum tersedianya sarana dan prasarana yang memadai untuk tempat pembuangan akhir sampah yang dihasilkan masyarakat. Kondisi sekarang mereka membayar pada desa lain sebagai kontribusi TPA (Tempat Pembuangan Akhir) masyarakat Desa Bokor. (5) Belum tersedianya Armada yang memadai untuk mengangkut sampah rumah tangga masyarakat desa Bokor secara rutin agar tidak terjadi penumpukan sampah di titik-titik tertentu.

Tujuan dari kegiatan pengabdian ini dari kondisi dampingan yang diharapkan adalah (1) Terjadinya perubahan pemahaman masyarakat yang benar terhadap mitos yang kurang tepat atas pembuangan limbah sampah rumah tangga ke sungai utamanya pembuangan sampah panpers yang tidak ada hubungannya dengan kemungkinan sakit "soloten" atau ruam pada bayi mereka. (2) Terjadinya perubahan perilaku masyarakat dengan mulai membuang sampah rumah tangga dengan benar pada tong sampah yang akan disediakan. (3) Munculnya kesadaran untuk memisahkan sampah rumah tangga dengan kategori sampah yang bisa di daur ulang, sampah yang tidak bisa di daur ulang, dan sampah yang memiliki potensi ekonomi jika diolah kembali. (4) Tersedianya sarana dan prasarana yang memadai bagi masayarakat untuk membuang sampah dengan pendistribusian tong sampah yang tepat. (5) Dengan pengolahan sampah yang tepat dapat memunculkan lingkungan yang sehat serta memberikan manfaat kembali secara ekonomis kepada masyarakat desa Bokor sendiri.

\section{METODE}

Berdasarkan tujuan kegiatan pengabdian masyarakat ini mengambil pendekatan PAR (Participatory Action Research). Metode action research ini digunakan untuk tidak membuat masyarakat desa Bokor dampingan sebagai obyek, tetapi menjadikannya subyek penelitian. Oleh karenanya solusi yang ditawarkan dilakukan dengan: 
1. FGD dengan Kepala desa beserta Perangkat Desa

2. Sosialisasi pentingnya perilaku hidup sehat dengan tidak membuang sampah sembarangan, kemudian disertai pemberian pemahaman pentingnya pemilahan Sampah Organik dan Unorganik

3. Pengecatan dan pendistribusian tong sampah ke rumah-rumah warga agar memudahkan menghitung volume sampah rumah tangga yang dihasilkan serta memulai mempraktikkan pemilahan sampah organik dan unorganik sebelum dibuang.

4. Desain ulang kartu iuran sampah agar terbentuk tertib administrasi untuk masyarakat desa Bokor dengan menambahkan peratuan-peraturan serta kewajiban- kewajiban yang harus dipenuhi oleh warga

Kegiatan KKM UIN Mengabdi melibatkan 12 mahasiswa yaitu (Ama Faridatul Husna Jamil, Rosidatul Halim Najib, Arrozy Anwar, Ridha Hadi, Neny Fathiyatul Hikmah, Siti Aliyah, Mohamad Ronal Huda, Silfia Putri, Faaula Dzurriyatul Adzkiya', Fatria Wijaya, Inggrid Quratulaini, Siti Qubbaila Chilyatul Jannah). Mitra yang terlibat adalah Perangkat Desa Bokor dan Karang Taruna dan PKK Desa Bokor Kecamatan Tumpang Kabupaten Malang.

\section{HASIL, PEMBAHASAN, DAN DAMPAK}

Pelaksanaan Kegiatan pengabdian masyarakat ini melalui tahapan-tahapan berikut ini:

\section{FGD dengan Kepala desa beserta Perangkat Desa}

Tahap pertama yang dilakukan adalah mengadakan FGD dengan kepala desa beserta apparat dan tokoh masyarakat Desa Bokor untuk menentukan prioritas kegiatan pengabdian ini. Dari hasil FGD dengan pihak aparat Desa Bokor dan Tokoh Masyarakat desa Bokor maka yang menjadi Fokus dalam pengabdian ini adalah bagaimana meningkatkan pola perilaku hidup sehat bagi masyarakat desa Bokor Kecamatan Tumpang yang dimulai dari pola pembuangan sampahnya. 


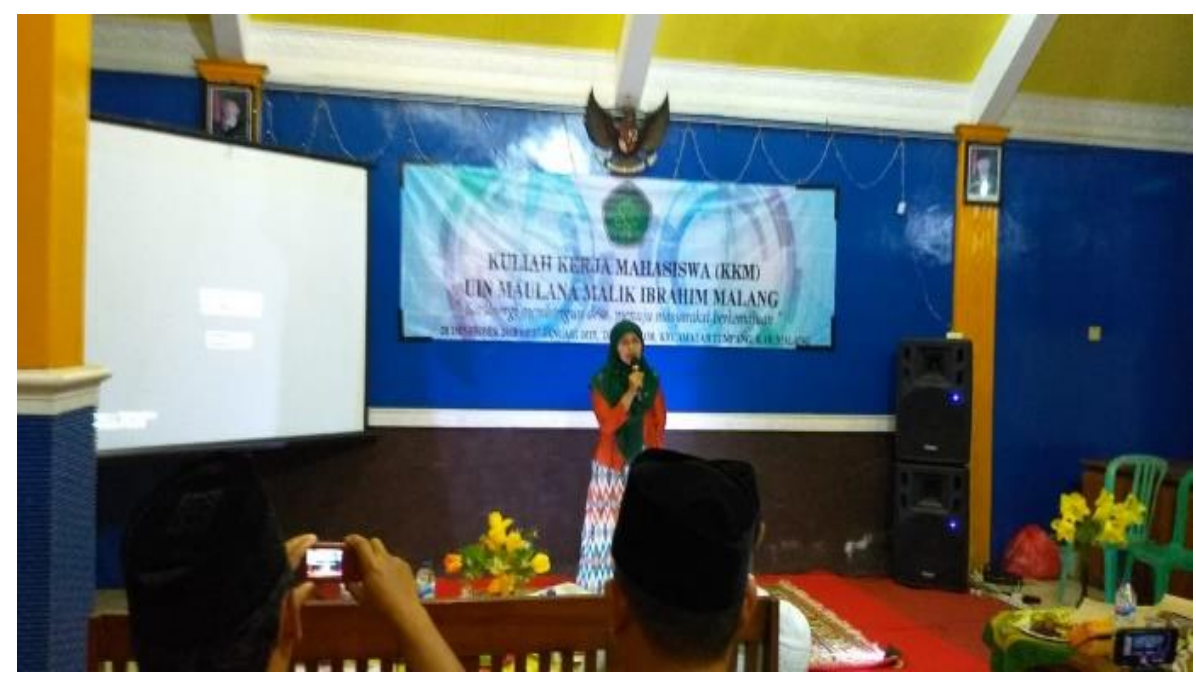

Gambar 1 FGD dengan Aparat dan Tokoh Masyarakat Desa Bokor

\section{Sosialisasi pentingnya perilaku hidup sehat dengan tidak membuang sampah} sembarangan, kemudian disertai pemberian pemahaman pentingnya pemilahan Sampah Organik dan Unorganik

Sosialisasi kegiatan pengelolaan sampah dan pemilahan sampah dilaksanakan dengan sasaran ibu-ibu PKK. Narasumber mensosialisasikan pengelolaan sampah dengan penayangan video tentang sampah. Dalam video tersebut menceritakan bagaimana dampak positif dan negatif sampah jika terus menerus tidak di kelolah dan bagaimana menurut pandang masyarakat tentang sampah. Dengan adanya media seperti itu narasumber menjelaskan bagaimana sampah itu jika terus dibiarkan terutama sampah plastik dan bagaimana dampak untuk jangka panjangnya. Dua video diputarkan kepada ibu-ibu PKK dengan tujuan supaya sadar akan sampah dan tidak membuang sampah sembarangan. Dokumentasi kegiatan dapat dilihat pada gambar 2.

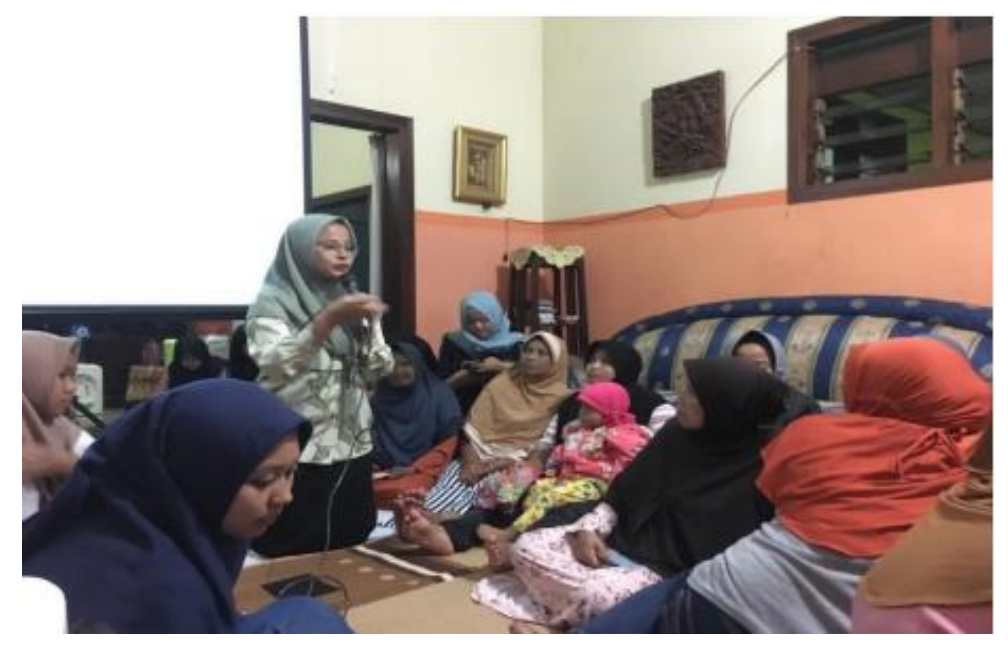

Gambar 2. Sosialisasi Pentingnya Perilaku Hidup Sehat Melalui Pemilahan Sampah Organik dan Unorganik 
Setelah penayangan dua video tersebut dijelaskan sampah terdapat dua macam yaitu sampah organik dan sampah non organik. Pengelolaan sampah non organik yaitu sampah yang tidak bisa terurai seperti sampah plastik, botol, kresek dan lain-lain, sampah -sampah tersebut tidak bisa terurai dalam artian bisa terurai tetapi membutuhkan waktu yang sangat panajng dan juga lama. Cara pengelolaan sampah non organik tidak dibuang ditempat sampah melainkan bisa dijadikan alat tukar berupa uang dengan dijadikan sebagai hiasan atau kerajinan tangan. Yang kedua yaitu sampah organik seperti sisa - sisa makanan, sayur -sayuran yang sudah busuk dan lain sebagainya. Cara pengelolaan sampah tersebut sebaiknya tidak langsung dibuang ditempat sampah alangkah baiknya di jadikan makanya hewan ternak seperti kambing, sapi, kerbau dan lain-lain. Dari penjelasakan sosialisasi sampah tersebut sudah cukup memberikan pengaruh bagaimana pengelolaan sampah yang sebenarnya jika sampah di jadikan sebagai hal remeh dapat berakibat fatal untuk masyakat sendiri khusunya masyarakat atau warga Bokor dan dampak salah satunya yaitu banjir. Adapun materi yang disampaikan dapat dilihat dari tabel 1 .

Tabel 1 Materi Sosialisasi dan Penanggung jawab Kegiatan

\begin{tabular}{|c|c|c|}
\hline No & Materi Sosialisasi & $\begin{array}{l}\text { Penanggung } \\
\text { Jawab }\end{array}$ \\
\hline 1 & Lingkungan Hidup & \\
\hline 2 & Klasifikasi Sampah & \\
\hline 3 & $\begin{array}{l}\text { Peran serta perempuan dalam pengelolaan lingkungan } \\
\text { hidup }\end{array}$ & $\begin{array}{l}\text { Nihayatu } \\
\text { Aslamatis Solekah }\end{array}$ \\
\hline 4 & $\begin{array}{l}\text { Potensi Pengelolaan sampah rumah tangga apabila dipisah } \\
\text { berdasarkan organic dan anorganic }\end{array}$ & $\begin{array}{l}\text { SE., MM. dan Tim } \\
\text { Mahasiswa }\end{array}$ \\
\hline 5 & $\begin{array}{l}\text { Diskusi atau Tanya jawab mengenai hal-hal yang berkaitan } \\
\text { dengan sampah rumah tangga dan pengelolaannya }\end{array}$ & \\
\hline
\end{tabular}

3. Pengecatan dan pendistribusian tong sampah ke rumah-rumah warga agar memudahkan menghitung volume sampah rumah tangga yang dihasilkan serta memulai mempraktikkan pemilahan sampah organik dan unorganik sebelum dibuang.

Sebelum mengadakan pendistribusian tong sampah tim pengabdian melakukan dan peserta KKM ikut serta membantu pengecatan tong sampah selama beberapa hari. Jumlah tong sampah yang akan di distrubusikan kepada masyarakat Bokor kurang lebih berjumlah 200 buah tong sampah. Dalam pendistribusiannya tong sampah setiap rumah tidak mendapatkan satu persatu akan tetapi mendaptkan satu tong sampah untuk dua rumah. Dalam pendistribusiannya yang pertama hanya pendistribusian tongnya saja tanpa ada tutup tong sampahnya yang dilakukan peserta KKM dan orang yang dipercayakan oleh pihak 
BUMDES, pendistribusian tong sampah kepada masyarakat atau warga desa Bokor hanya menggunkan gerobak kecil. Setelah pendistribusian tong sampah ke esok harinya pendistribusian tutup tong sampahnya dengan menggunakan pick up yang dibantu oleh peserta KKM untuk seluruh masyarakat atu warga desa Bokor, dapat dilihat pada gambar 2.

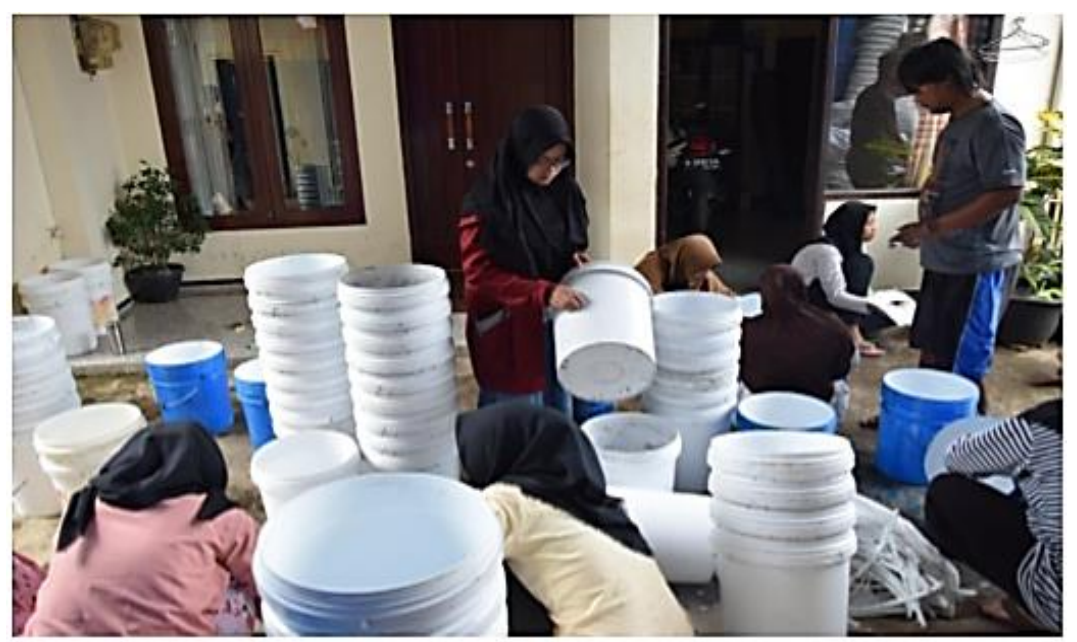

Gambar 2. Proses Pengecatan Tong Sampah

\section{Desain ulang kartu iuran sampah agar terbentuk tertib administrasi untuk masyarakat desa Bokor dengan menambahkan peratuan- peraturan serta kewajiban- kewajiban yang harus dipenuhi oleh warga}

Pembuatan kartu disini yang dimaksud yakni tim membantu mengupgrade desain kartu, yang mana memang sebelumya kartu itu sudah ada, namun di dalam kartu yang lama tidak ada peraturan tentang penggunaan dan pembayaran sampah, sedangkan tim menambahkan terkait peraturan-peraturan dan syarat- syarat yang harus dipenuhi oleh masayarakat dalam melakukan pembayaran serta catatan bahwa kartu yang digunakan itu sebagai syarat administrasi di desa. Fungsi adanya kartu pembayaran itu yakni untuk mengingatkan warga tentang pembayaran. Sehingga diharapkan warga bisa membayar tepat waktu dengan adanya kartu pembayaran sampah yang lebih detail isinya yakni terdapat peratuan- peraturan serta kewajiban- kewajiban yang harus dipenuhi oleh warga. Terkait desainnya kartu pembayaran sampah, mengikuti arahan dan instruksi dari BUMDes Bokor dengan menambahi peraturan- peraturan dibalik kartu nya menggunakan aplikasi potoshop untuk mempermudah pembuatan serta penyetakan kartu dengan desain tampak bolak balik. Sebagaimana gambar 3. 
(Tampak Depan)

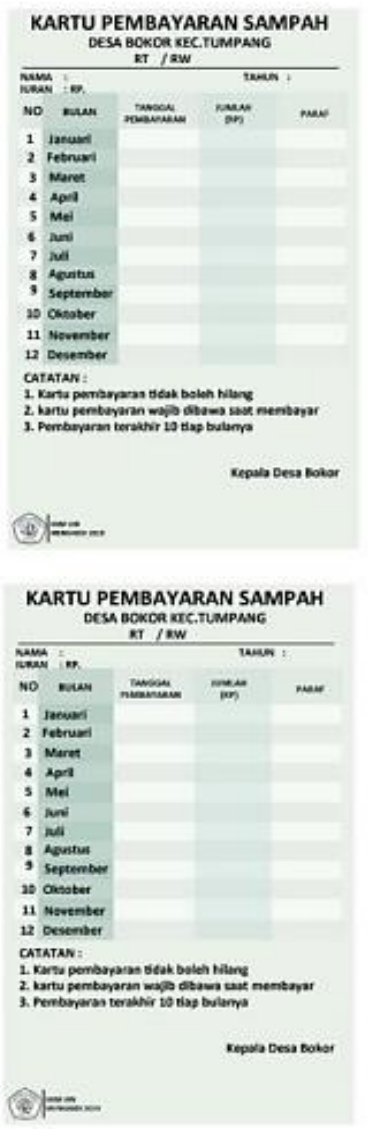

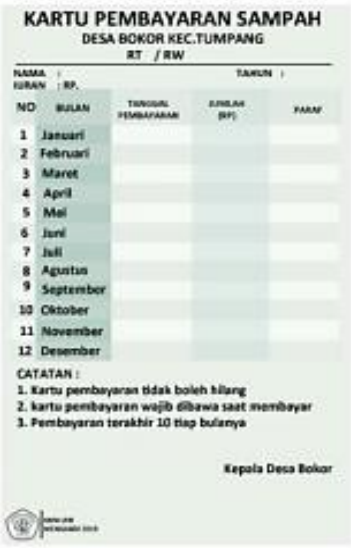

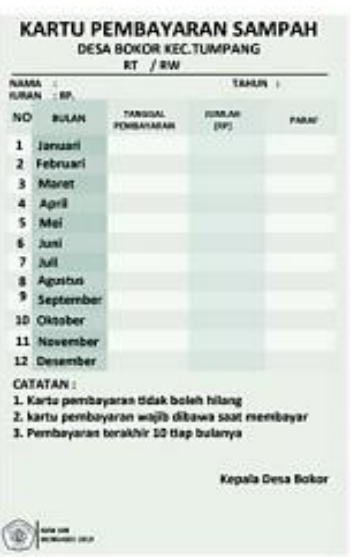

(Tampak Belakang)
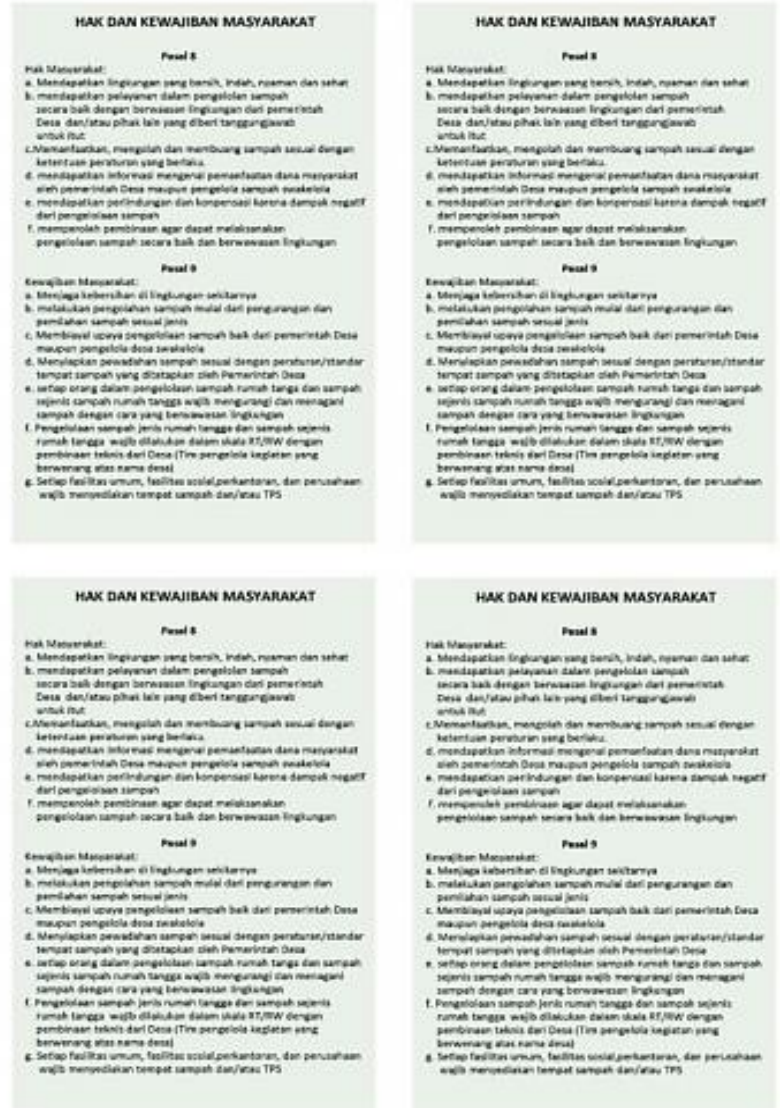

Gambar 3 Desain Kartu Iuran Sampah Tampak Depan dan Belakang

Berdasarkan evaluasi pelaksanaan kegiatan, dapat diidentifikasi faktor-faktor pendukung seperti (1) Kepala Desa dan seluruh aparat desa beserta tokoh masyarakat mau diajak untuk bekerja sama dan sangat membantu pelaksanaan kegiatan pengabdian.(2) Antusiasme ibu-ibu dan remaja masjid di lokasi pengabdian dalam mengikuti program pengabdian yang dilakukan. (3) Dukungan dana Bum Des untuk menyediakan sarana tong sampah yang akan didistribusikan ke masyarakat desa Bokor. Sedangkan faktor penghambat dalam pelaksanaan program pengabdian ini, antara lain: (1) Pada kegiatan ini hanya sampai pada sosialisasi bahayanya membuang sampah secara sembarang atau di sungai, dan pemberian penyadaran untuk memilah sampah tersebut ke dalam kelompok organik dan anorganik, belum sampai pada pelatihan pengolahan sampah rumahtangga tersebut.

\section{SIMPULAN}

Dari kegiatan pengabdian ini dapat disimpulkan bahwa solusi yang ditawarkan cukup memberikan dampak, seperti munculnya pemahaman yang tepat bahwa tidak ada kaitannya kemungkinan sakit ruam pada bayi mereka dengan membuang sampah panpers tidak 
disungai melainkan di tong sampah yang sudah disediakan, kemudian terjadi perubahan perilaku masyarakat dengan membuang sampah rumah tangga ke tempat yang tepat. Selain itu dari hasil evaluasi dari kegiatan pengabdian masyarakat ini, para warga mulai memilah sampah organik dan unorganik, sehingga tujuan ketiga tercapai. Untuk tujuan keempat terciptanya sarana dan prasarana memang belum sepenuhnya terpenuhi, mengingat keterbatasan dana BUMDES maka sarana 1 tong sampah digunakan untuk dua rumah memang dirasa kurang, namun paling tidak sudah ini bisa dikatakan sebagai langkah awal untuk pemenuhan sarana dan prasarana agar tercipta lingkungan yang sehat dan bersih.

Untuk pendampingan selanjutnya dapat dilakukan pelatihan pengelolaan sampah rumah tangga seperti pemanfaatan sampah organik dan sampah unorganik yang sudah dipilah oleh masyarakat Desa Bokor tersebut.

\section{UCAPAN TERIMAKASIH}

Ucapan Terimakasih diucapkan pada LP2M UIN Maulana Malik Ibrahim Malang yang telah menfasilitasi kegiatan KKM UIN Mengabdi tahun 2019, serta kepada Bapak Muassan selaku Kepala Desa Bokor Kecamatan Tumpang Kabupaten Malang dan Mahasiswa KKM kelompok 62 dan 197

\section{DAFTAR PUSTAKA}

Bhatti, S.H., Saleem, F., Zakariya, R. and Ahmad, A. (2019), "The determinants of food waste behavior in young consumers in a developing country", British Food Journal, Vol. ahead-of-print No. ahead-of-print. https://doi.org/10.1108/BFJ-06-2019-0450

Damanhuri, E., dkk. 2004. Diktat Kuliah Pengelolaan Sampah. Edisi Semester I 2004/2005. Bandung: ITB.

Sahil, J., Al-Muhdar, M. H. I., Rohman, F., \& Syamsuri, I. (2016). Sistem pengelolaan danupaya penanggulangan sampah di Kelurahan Dufa- Dufa Kota Ternate. Jurnal BIOeduKASI, 4(2), 478-487.

Schanes, K., Dobernig, K. and Gözet, B. (2018), "Food waste matters-a systematic review of household food waste practices and their policy implications", Journal of Cleaner Production, Vol. 182, pp. 978-991. https://doi.org/10.1016/j.jclepro.2018.02.030

Stangherlin, Isadora do Carmo; Duarte Ribeiro, Jose Luis; Barcellos, Marcia (2019), "Consumer behaviour towards suboptimal food products: a strategy for food waste reduction”, British Food Journal Vol. 121 No. 10, 2019 pp. 2396-2412. DOI: 10.1108/BFJ-12-2018-0817 
Stangherlin Isadora do Carmo, Barcellos Marcia Dutra de (2018), “Drivers and barriers to food waste reduction”, British Food Journal. https://doi.org/10.1108/BFJ-12-2017$\underline{0726}$ 